\title{
Children's Health, Maternal Labour Supply and Wealth Accumulation: Theory, Evidence and Policy Approach
}

\section{Mbu Daniel Tambi*}

Department of Economics, University of Bamenda, Dschang, Cameroon

\begin{abstract}
Understanding the impediments of children's health on maternal labour and wealth accumulation in Africa is critical. The preoccupation of this study has been to develop a conceptual framework based on exploring the health-labourwealth relationship. This is, in an attempt to show the centrality and importance of children's health in understanding: maternal labour supply and wealth accumulation for broader appreciation. Based on empirical evidences, we observed that children's health positively and significantly influenced maternal labour and also strongly corroborates with wealth accumulation. From policy point of view, investing in children's health can motivates population growth, increase the supply of labour, promote savings and alleviate poverty.
\end{abstract}

Keywords: Children's health; Maternal labour; Wealth accumulation; Theory; Evidence; Policy

\section{JEL Classification: M1 D2 T3}

\section{Introduction}

The policies for children's health, maternal labour and wealth accumulation throughout the world, require thorough understanding of both the processes, determinants and causal paths that underlie the intricate relationships among them. This is judged difficult, undetermined and only casually understood, yet it has been observed that improving health around the world today is an important social objective which has obvious direct payoffs in terms of longer and better lives for millions and indirect payoffs through accelerating economic growth. For instance, wiping out malaria in Sub-Saharan Africa (SSA) could increase the continent's per capita growth rate by as much as $2.6 \%$ a year. A recent report by the World Health Organization's (WHO) commission on macroeconomics and health (2001) reveals that, the burden of disease in certain low-income regions stands as a stumbling block to economic growth and must be tackled frontally and centrally in any comprehensive development strategy, hence improving the health and longevity of the poor is an end in itself and fundamental goal of economic development in Africa.

Health therefore is one of the most important assets a human being has; it permits us to fully develop our capacities and if this asset deteriorates or it is not developed completely, it can cause emotional, physiological, psychological, and mental weakening, causing obstacles in the lives of people. Today, it is possible for every person to expect to live a long and healthy life from which its economic value is huge, given that health gains have many economic consequences widespread in economic well-being. Thus, an escape of ill-health traps is greatly associated with increase productivity, domestic savings and investment. This is why the relationship between health and income has life cycle models and authors have explained how one's health status can determine future income, wealth and consumption in Africa [1].

The economic benefit from improved children's health comes in part, from reduced child mortality and from reduced costs of healthcare for children. These economic benefits are dominated by productivity gains from improved infant health, which releases extratime at the disposal of mothers to participate in the labour market and from increased schooling and cognitive ability attributable to health in early childhood [2]. According to empirical studies, better children's health improves the timing of school entry, the number of years completed, the learning that takes place per year of schooling and the actual achievements in school, which are commonly shown to lead to increased lifetime earnings in Africa and elsewhere [3].

SSA has experienced a number of dramatic successes in infant health in the decades since independence particularly with respect to child mortality and morbidity and the eradication or reduction of specific diseases. Successes include vaccination programs against measles and other childhood illnesses, the expansion of oral rehydration therapy for treating infant diarrhoeal diseases and the near-elimination of river blindness and Guinea worm [4]. At least until the 1980s under-five mortality fell sharply in SSA and this led to increased maternal labour supply as well as improved economic wellbeing. However, SSA remained behind most of the developing world in child and other health indicators as progress in children's health has slowed considerably in the last twenty years. From 1990/2006 the share of malnourished children under five fell slightly, from $32 \%$ to $28 \%$ [5] under-five mortality showed some progress, falling from 184 to 157 per 1000 in the period, but this improvement is smaller in Africa as compared to other regions.

In Africa, the importance of investing in child health has been much less appreciated or greatly underestimated by analysts and most decision makers as well as partner international donor community [5]. Equipped newborn centers are only in the big cities, the proportion of infants correctly immunized against diphtheria, tetanus and whooping cough in 1996 was $46 \%$ in central Africa and the proportion of infants reaching their first birth day that have been correctly treated against measles and tuberculosis is 54\% [6]. Breast feeding is almost $90 \%$ and more in rural zones; further, many mothers in the rural communities still give birth at home [7]. All these, have fuelled poverty and worsened economic well-being and maternal labour force participation in Africa.

*Corresponding author: Mbu Daniel Tambi, Department of Economics, University of Bamenda, Dschang, Cameroon, E-mail: tambi2015@yahoo.co.uk

Received July 24, 2017; Accepted August 10, 2017; Published August 18, 2017

Citation: Tambi MD (2017) Children's Health, Maternal Labour Supply and Wealth Accumulation: Theory, Evidence and Policy Approach. Health Econ Outcome Res Open Access 3: 135. doi: 10.4172/2471-268x/1000135

Copyright: @ 2017 Tambi MD. This is an open-access article distributed under the terms of the Creative Commons Attribution License, which permits unrestricted use, distribution, and reproduction in any medium, provided the original author and source are credited. 
This study attempts to look at the: theoretical insights on Children's Health (CH), Maternal Labour (ML) and Wealth Accumulation (WA) and on the intersection of children's health on maternal labour and wealth accumulation; the empirical evidence on the relationship between $\mathrm{CH}$ and $\mathrm{ML} ; \mathrm{CH}$ and WA as well as between ML and WA as well as fresh insights for $\mathrm{CH}$ policy for ML and WA that has emerged over the years. Thus, this study attempts to tests the following hypotheses: (1) Children's health is instrumental in accounting for maternal labour and (2) children's health is strongly associated with higher levels of wealth accumulation.

\section{Literature Review}

The concept of child health is still not quite understood even to health personnel in SSA and governments policy towards international organizations interested in child health are not flexible [8]. Whereas child health problems remain the leading cause of ill health and death for women of child bearing age, impoverished women, especially those living in rural zones suffer disproportionately from unintended pregnancies, maternal death and disability, sexually transmitted infections and other problems related to their reproductive system and sexual behaviour [9]. Moreover, Baye and Fambon [2] observed that, in much of the healthcare demand literature, attempts at establishing linkages between health consumption and health production (wealth accumulation, productivity) have been embarked upon outside Africa [10] whereas knowledge on these issues are widely needed by very little effort in this direction has been made using data from SSA [11] the only studies that have attempted to tackle some aspects of reproductive health care, maternal labour and wealth accumulation are Baye and Fambon [2]; Tambi et al. [12]. No attempt in this same direction has been made in the light of theory, evidence and policy. In an effort to close this gap and contribute to this literature, we shall examine the thesis, anti-thesis and the synthesis of these concepts as well as derived economic policies to ameliorate the relationship.

In modern literature, child health is the condition of the body or state of well-being from zero to five years (0-59 months) strongly determined by four indicators: Genetics, parent lifestyles, environment and socioeconomic status of guidance or parents. Generally, health has two distinct phases: Positive health (well-being) and negative health (ill health). The positive phase consists of the aspects of health and human life in general, strongly associated with the concept of "fitness" while negative phase is determined by the presence of disease, illness, deformity, qualitative unwanted states, injury, disability and handicap. The relationship between the two phases is not clear-cut [10] and they may not be systematically related at all.

Child health is multi-dimensional and different dimensions of health are likely to have different effects on economic well-being. Bategeka et al. [13], underscore that, with the progress of medicine, the concept of reproductive health, involving child health has now widened to mean "a state of complete physical, mental and social well-being". This definition relates not only to the improvement of child well-being, but also implies that parents should have access to treatment and that children affected by physical, mental and social disorders should be rehabilitated. Thus, the measurement of children's health is not simple and child health indicators are numerous not-with-standing, the multi-dimensional characteristics of child health have been clearly demonstrated in Tannahills model of health production domains.

According to Kiiskinen [14], Tannahill's model stipulates three overlapping spheres of health activity (education, prevention, protection) that directly or indirectly influence child health. This literature is consistent with the study of Ako et al. [8] to include not only curative measures but prevention, protection and health knowledge. Tannahill's model and children's health [Child health has moved from a stage where it used to be considered as concerning only the child to a level where it involves the parent] (Figure 1). It has also moved from curative activities alone to include both curative and preventive activities. The scope of $\mathrm{CH}$ has also widened. This has been partly due to the increasing demands for better health care for infants and also for the increase in life expectancy.

The intersections of these spheres divide children's health into seven domains $[10,14]$ :

1. Prevention: Immunisation, screening, self-help groups (prenatal care)

2. Preventive child health education: Educational efforts to influence life-styles encourage the uptake of preventive services etc. (mother socio-economic characteristics).

3. Preventive child health protection: Water fluoridation, legislation to restrict smoking, fiscal policy for tobacco and alcohol (child development and nutrient intake).

4. Protective child health education for preventive purposes: Lobbying for protective legislation, efforts to influence the social environment to enhance the probability of effective preventive services being provided (parental productivity).

5. Health education for child well-being gains (positive health education). Education aimed at encouraging changes in an individual's health behaviour in order to promote healthy gains, e.g. encouraging physically more active use of leisure time (nutritional complement).

6. Health protection for child well-being gains (positive health protection): provision of public funds to promote the construction of leisure facilities, development of work place, no-smoking policies on the grounds of general health benefits of clean air etc. (child development and schooling).

7. Protective health education for child well-being gains: e.g. lobbying policy makers for more leisure facilities, and encouraging and supporting members of the community to express a desire for such facilities (Schooling performance, attendance and adult wealth and productivity). The definitions of domains seem to cover mostly non-curative activities that can be assumed to have direct and indirect effects on child health.

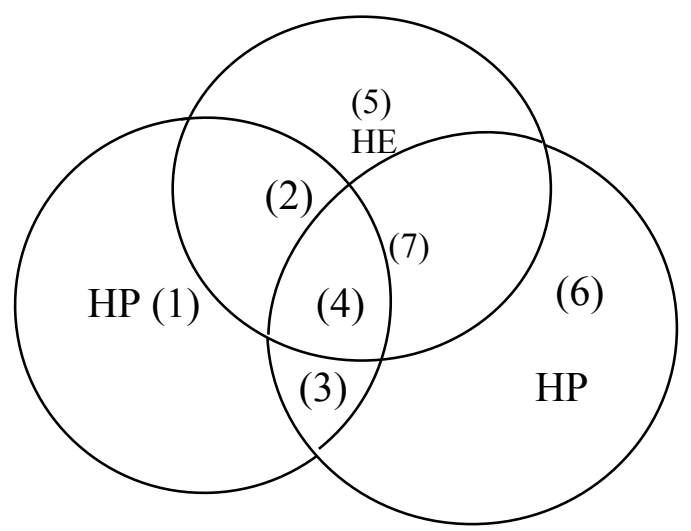

Figure 1: Tannahill's model and children's health. From the graph: HE: Health Education; HP: Health Prevention; HP: Health Protection. 
Considering the different domains as illustrated in Figure 1 above, we distinguish child health strategies by the type of decision maker involved in the activity, since different decision makers require different theoretical frameworks. It is likely that those child health production strategies that are based on lobbying policy makers and legislators (domains 4 and 7) are best evaluated by using the theory of organisations, whereas the rest of the domains fall within the theory of consumer behaviour. This study concentrates on the consumer aspects of health production. These domains correspond to the second objective of our study that deals with child linkages to maternal labour, wealth accumulation and deriving policy implications. The remaining strategies (domains 1-6) can further be divided into two categories depending on whether their effects are more appropriately analysed by models of household production or consumer demand. Productive aspects are more important in the strategies which use education and other methods to provide information in order to increase individuals' knowledge about child health effects of their behaviour (domains 2 and 5 ), which is assumed to result in improved allocative or productive efficiency of consumer choices. The other strategies are designed to have their primary impact on child health through imposed changes in the supply and demand conditions of goods with known harmful or beneficial effects on health (domains 1, 3 and 6). These domains are well fitted in the first objective of our study that deals with the determination of child health production (determinants of children's health).

The dimension of health that is of most concern in this study is child health. Children's health is the outcome of consumption of both reproductive healthcare and other goods and services. The reproductive health indicators include maternal mortality, infant mortality, total fertility rates, weight at birth and child survival rate while the key components of child health are family planning, safe delivery services, prenatal and postnatal care, treatment of placental malaria, nutrients supplements during pregnancy and behaviour that promote fetal growth. The utilization of child healthcare inputs is constrained by market and non-market factors. The market factors include availability of children's health inputs and their prices, and household income. The non-market factors include household characteristics and individual characteristics such as age, education, health status and the information they possess about the quality of children's healthcare services. The concept of children's health can be further explained by deeply examining the definition and measurement of child health.

\section{Theoretically Linking Children's Health, Maternal Labour and Wealth Accumulation}

In this section we are interested in establishing the theoretical concepts relating child health to maternal labour, child health and wealth accumulation and the possible relationship existing between the three concepts.

\section{Theoretically linking children's health and maternal labour}

According to Ranis et al. improve prenatal care and nutrition has been shown to have direct effects on maternal labour productivity especially among poorer individuals. A range of labour productivity gains has been observed associated with calorie increases in poor countries, for instance, studies of farmers in Sierra Leone, sugar cane workers in Guatemala and road construction workers in Kenya. In these cases productivity enhancement appears to follow fairly immediately as current intakes of calories or micro-nutrients are increased. Improve prenatal care, nutrition and medical care of the child reduces medical expenditure on the child in times of illness, the psychological trauma of staying at home to take care of the child is also reduced, hence giving the mother the extra time to participate in the labour market.

The time spent by women in activities such as food preparation, breastfeeding, collecting water and fuel and seeking preventive and curative medical care is an important input into the production of infant or child health. Mothers, who work, however, may lack the time to adequately breastfeed or prepare nutritious foods for their young children or make use of public services designed to improve child nutrition. Although market substitutes for some time-intensive inputs exist (prepared foods, hired domestic help), these may be too costly for many women for many other time-related inputs into health, there are unlike to be functioning markets. Working women may rely on other members of the household to provide childcare while they work, but the quality of care provided by these substitutes; especially if they are older children may be poor. Thus the relationship between female labour and child health is even more complex. On the one hand, labour force participation can have an adverse impact on child health as the child will not get full attention from the mother and may even forgo the benefits of breastfeeding. This will probably happen in those families where because of poverty the mother must participate in the labour market soon after delivery. On the other hand, the mother's work force participation will enhance the family income which will in turn have a positive impact on child nutrition and health. Thus, the eventual outcome of female labour force participation on child health depends on the relative influence of these two routes of causation.

The empirical evidence on this issue also reflects this conflict. Many of the international studies cited in Sherraden [15], suggest an inverse relationship between child health and female labour force participation. Some studies suggest that, after controlling for family income, children are better fed and looked after in households where women work. In such households a large proportion of the family's earnings are expended on child care and related activities. A study by Kanter [16] in Kerala indicated a positive association between female earnings and child nutrition, but a similar association between paternal income and child nutrition was not found. Another study of poor households in Kerala and Tamil Nadu categorically states that "eliminating female work, even if it means some improvement in male employment, would have a very negative effect not only on the females themselves but also on the families the support [17]. On the contrary, some studies indicate a direct relationship between child health and maternal labour force participation [18]. For instance, a recent Indian study reported an adverse impact on child mortality of the mother's participation in the labour force [18]. The authors trace this to the inability of working mothers to give adequate care to infants and to breastfeed them properly. This conceptual linkage can be summarized in Figure 2.

\section{Theoretically linking child health and wealth accumulation}

Mirvis and Chang [19], describe three major path ways through which child health is related to asset endowment. Firstly, child ill health or disease causes the direct loss of income either through medical care or the labour market. By virtue of child poor health, the parent will spend much money in buying medication and so reducing household wealth. Child illness provokes the physical depreciation of the mother due to psychological trauma, because of these; the mother will forgo future income by not going to work. All these have negative consequences in household asset endowments.

Secondly, poor child health has life cycle consequences. Early childhood or even in utero diseases reduce both cognitive and physical 

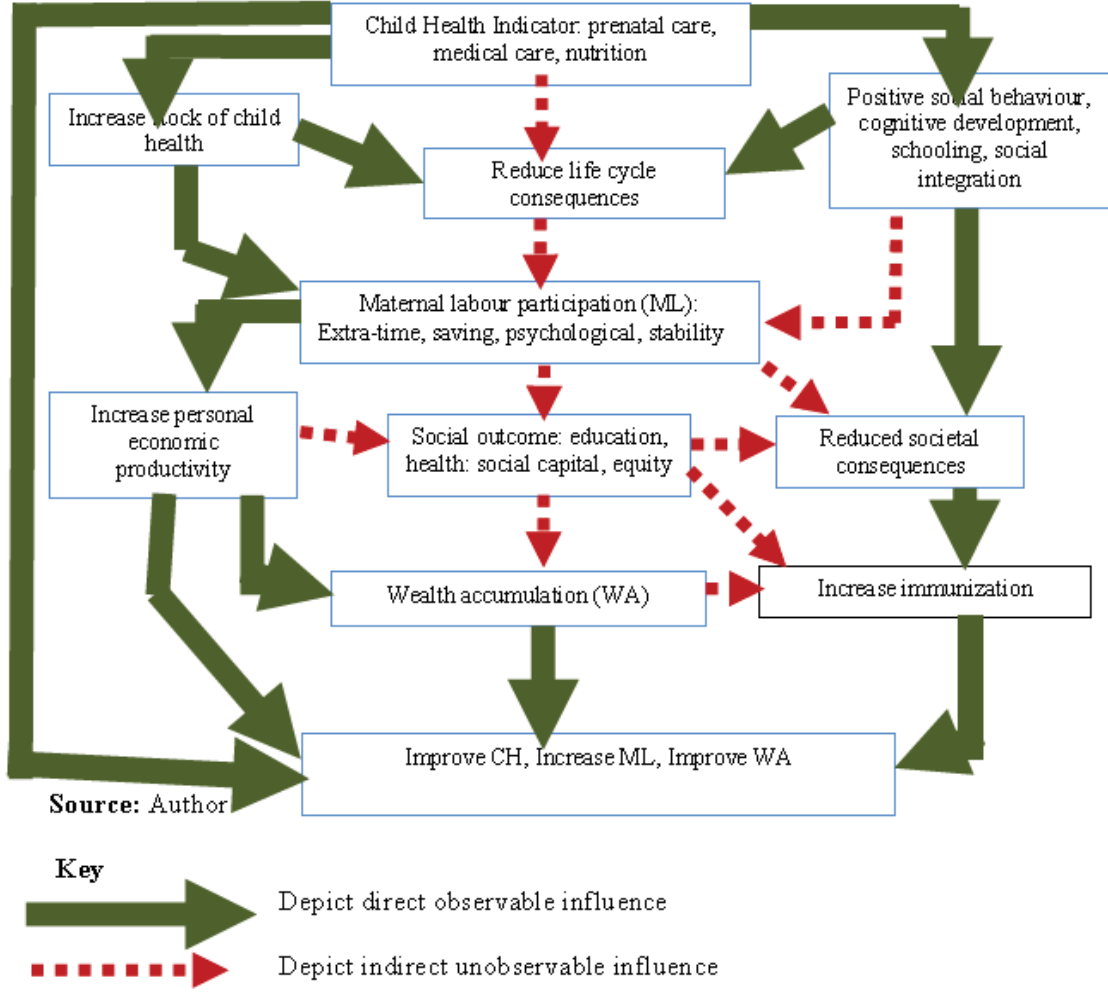

Figure 2: Consolidates the sub linkages between child health, maternal labour and wealth accumulation. This study has tests the hypothesis that: $\mathrm{H} 1$ : Children's health is instrumental in accounting for maternal labour. H2: Children's health is strongly associated with higher levels of wealth accumulation.

capacities later in life, both of which reduce economic productivity and household income/wealth. These effects are due to direct biological consequences of diseases as well as to lower educational attainment. Sick children miss school and commonly dropout. Thus, childhood illness results in the dual burden of limited education and limited native ability. These effects of poor health on personal economic capacity may be intergenerational, that is the poor health of one generation may affect the economic productivity of subsequent generations, hence wealth accumulation. Another remarkable relation is between child health and fertility rates. The evidence indicates that poor households compensate for children's deaths by having large numbers of children. The fertility rates in countries with high infant mortality rates may be five times greater than rates in countries with low infant mortality rate. Thus, poor child health leads to large families with low "parental investments" per child, hence hindering future income/wealth and economic wellbeing [17].

Generally, poor health in a population produces societal consequences that reduce household wealth accumulation beyond the direct effects on individual workers. Poor health in an area reduces external investment and tourism. The workforce is affected as employee turnover and skilled workers leave the area because of fear. Similarly, illness in a society diverts communal resources to healthcare and away from other needs. A greater proportion of overall expenditures are directed to healthcare while overall tax revenue is reduced due to lower personal economic productivity. Social programs become fully occupied caring for the sick rather than attending to other social programs such as education and income generating activities that increase the accumulation of wealth. This theoretical relationship is summarized in Figure 2.

\section{Derivation of Hypotheses}

As seen above, the systematic construction of the sub linkages between child health, maternal labour and wealth accumulation allows us to distil, constructively some of the testable hypotheses ( $\mathrm{H} 1$ and $\mathrm{H} 2$ respectively). As noted in the health literature, strengthening maternal and child health services can bring benefits to the overall health system, which can enhance access and use of a broad number of reproductive healthcare services as well as improve economic productivity for the society. The key determinants of child health include nutritional status and age of the mother, mother's immunization against preventable diseases and behavioural change during pregnancy. Other factors such as areas of residence, which are proxies of availability of healthcare and nutrients, also affect the health of the child in the uterus (Figure 2).

Concerning hypothesis one, it is widely recognized that women in developing countries have dual roles as generators of household income and as primary caregivers to their children. Many policies directed at reducing poverty or malnutrition involves one or the other of these roles. Programs to reduce child malnutrition, for example, typically target mothers as caregivers. However, because of the time constraints women face, there are potential conflicts between women's different activities about which policy makers are rarely informed. Nutrition interventions have not usually considered the barriers to participation in such programs facing mothers who, either by choice or necessity, have entered the labour force. Similarly, policies directed at improving female employment opportunities typically ignore women's important role in household activities related to children's healthy development. Many studies have shown a negative effect of children's poor health on maternal employment or work hours, Salkever [20] estimated 
a reasonably large-in magnitude and negatively-signed coefficient for disability in an employment specification. Kanter found a very small, statistically insignificant point estimate of the effect of child disability on female heads' labour force participation. Other studies have found significant and large-in-magnitude effects on work and welfare participation. Wolfe and Hill found a reduction in labour force participation that is nearly equal to the estimated impact of a mother's own poor health. Wolfe and Hill, using a sample from the 1980 national medical care utilization and expenditure survey, found that the mean perceived health status of all family members has a negative effect on single mothers' labour hours. An independent negative effect of child health on hours is identified. The estimated effect of child disability on single mothers' LFP in Salkever [20] is significantly negative at standard confidence levels (Figure 2). Wolfe and Hill using a sample of approximately 1,600 single mothers also found that child disability reduces labour force participation.

In Meyers et al. [21] mothers of children identified as disabled are asked whether their children's condition constraints the amount or type of work they can do. Meyers et al. [21] found that mothers of more severely disabled children or multiple disable children, more often answered this question affirmatively. Meyers et al. [21] found the number of disabled children in a family and the severity of disability both lower the probability that the mother works, although the latter finding is not robust. Salkever [20] analyze the impact of children's disabilities on the duration of welfare spells; in contrast to Wolfe and Hill, they found evidence that mothers of severely disabled children are significantly less likely to leave domestic chores for work. In the same line, wives' employment is apparently reduced by a disabled child's presence; more studies examine female heads with inconclusive results. This is not surprising given the widely varying definitions of child disability across studies and the frequently small samples. While some studies analyze work hours, employment (usually defined as working positive hours) is almost always the primary measure of work activity. Previous analyses take a static approach and none acknowledge the potential influence of unobserved maternal characteristics on labour market activity. This theoretical observation derives our hypothesis $\mathrm{H} 1$ as indicated in Figure 2.

With respect to hypothesis two, we observed that empirically, home ownership is associated with a variety of opportunities and provides a feeling of stability and stake-holding [22]. For example, Sherraden use household savings and home value in studying asset effects on attitudes and behaviours of parent and children. Sherraden use the total value of savings and home ownership in studying mothers' expectations and children's educational performance. They observed that the savings and home asset strongly correlates with children's educational performance (Figure 2). In addition, the development approach on household asset endowments has focused on asset-building interventions and measured assets accumulated through these interventions in relation to health. Examples include measures of participation and the amount of savings in Individual Development Account programs. Here, asset definitions and measures from the development perspective are believed to positively correlating with health, despite the fact that, it does not fully capture the complexity of the asset accumulation process and asset effects [22]. This theoretical observation therefore, derives our hypothesis $\mathrm{H} 2$ as shown in Figure 2.

\section{Methodology and Empirical Specification}

\section{Econometric issues and models linking child health to MLFP}

As seen above, we used the economic model of the family developed by Becker [23] and as applied by Frijters et al. this forms the conceptual basis for our analysis of the consequences of child health on Maternal Labour Force Participation (MLFP). Based on these authors, the relationship between child's health and maternal labour force participation can be described within the framework of a simple household production model [20]. Thus, the generic model of maternal labour force participation for family $i$, is assumed to be:

$$
M L F P_{i}=\lambda_{1} \chi_{i}+\delta_{1} w a z_{i}+\varepsilon_{1 i}
$$

Where $\operatorname{MLFP}_{i}$ is a binary variable representing mother i's participation, $\chi_{i}$ is a vector of exogenous characteristics such as: Sex of household head, residence, education, age, time taken to fetch water, tetanus immunization status, occupation and marital status. The $\mathrm{waz}_{\mathrm{i}}$ is child health and $\varepsilon_{i}$ is a random error term. The coefficient $\delta_{1}$ is the parameter of interest and represents the impact that child health has on MLFP. Equation (1) can be used to estimate the Ordinary Least Square (OLS). Unfortunately, this single-equation estimates may be upward or downward biased depending upon the effect that maternal employment has on child health and on the correlation between omitted variables and child health. Thus, if maternal employment has a positive impact on child health, then we would expect the OLS estimate of $\delta_{1}$ to be biased upward and vis-a-versa. This two-way causality and couple with some important missing variables in our data, this may cause the classical endogeneity problem.

To avoid this bias, confounded by the problem of variables that is missing in empirical data, we use a two stage least squares estimation approach. Thus, the first-stage equation in this approach is:

$$
h a z_{i}=\beta_{1} \chi_{i}+\alpha_{1} L C S_{i}+\pi_{1 i}
$$

Whereby LCSi is large child size at birth, as indicated by Frijters et al. the 2SLS model should capture the causal effect of child health for those children whose health is affected by size of child at birth. Importantly, though haz is ordinal, 2SLS estimates of $\delta_{1}$ can be interpreted as estimating the average marginal effect of a unit increase in haz ${ }_{\mathrm{i}}$ for children whose health is affected by large size at birth. Before presenting the 2SLS estimates, we present a reduced form analysis of child health; here we would expect to observe mothers with small size children to have lower participation, because child health is negatively affected by size of the child at birth. Given that the 2SLS estimation allows us to scale this bias effect into the effects on an increase in our ordinal child health measure; hence we present our main result of 2SLS second-stage estimates.

\section{Hypothetical mechanism linking child health to wealth accumulation}

Child Health $(\mathrm{CH})$ can affect Household Wealth Accumulation (HWA), either positively or negatively through several ways not-withstanding, child health is generally associated with increase household wealth accumulation and they can be jointly estimated though each has its own interpretation. As stated in most child health literature, family health, especially child and mother health and socio-economic characteristics, are important components of wealth accumulation and poverty reduction because they shape future human livelihood opportunities. Good health at childhood does not only affect the biological growth potential, risk of morbidity and mortality in later years of life. Thus, children's health can be considered an important input in the well-being production function of the householdregistering mainly indirect effects on household income via the extratime, peace of mind and potential savings. The structural equation presenting the above relationship can be express as follows: 


$$
H W A_{i}=r_{1} \eta_{b}+\sum_{j} k_{j} W A Z_{j}+\varepsilon_{1} j=1 \ldots . .3
$$

where, HWA is household wealth accumulation; $\mathrm{WAZ}_{\mathrm{i}}$ is child health (weight-for-age $\mathrm{z}$ score); $\mathrm{r}_{1}$ is a vector of exogenous covariates (household residence, sex of child, parent age...); $\mathrm{k}_{1}$ is the parameter of the potentially endogenous explanatory variable (waz) in the wealth function, $\eta_{b}$ is the vector of parameters to be estimated and $\varepsilon_{1}$ is the error term that captures both random effects and unobservable variables.

In the recent literature, the endogenous explanatory variables are commonly referred to as "treatment variables". This terminology stresses the fact that the most credible way to measure the effect of an endogenous variable on the outcome variable of interest (i.e., to identify treatment effect) is to vary the endogenous variable experimentally. In an experimental setting, this variation is achieved through a random assignment of units of study into treatment and control groups. The word "treatment" is used to indicate that a section of the study sample is "treated" (its characteristic of interest, such as immunization, is varied exogenously). Since this variation occurs when other causal factors are held constant, it is possible to identify the effect of the characteristic on outcome variable of interest (waz). In the absence of an experiment, such a variation is achieved through an econometric procedure, with the aid of a structural model [24].

The estimation of the parameter $\mathrm{k}_{\mathrm{j}}$ would show the effect of child health on household wealth accumulation. Following Bategeka et al. [13] the reduced form of child health generating wealth accumulation estimation strategy can take the following form:

$$
W A Z_{j}=r_{2} \eta_{\text {wazj }}+r_{2} \Omega_{\text {wazj }}+\varepsilon_{2 j}
$$

Where, $r_{2}$ is a vector of exogenous instrumental variables affecting WAZ but have no direct influence on wealth, $\eta_{\text {wazj }}$ and $\varepsilon_{2 j}$ are vectors of parameters of exogenous explanatory variables in the reduced form child health function to be estimated and $\varepsilon_{2 j}$ is the error term that captures both the random effects and other relevant but unobservable characteristics or complementary input? This equation (3) is the structural equation of interest that is the wealth accumulation production technology whose parameters are to be estimated. Equation (4) is the linear projection of the potentially endogenous variable (WAZ), on all the exogenous variables. The instrumental variables (2SLS) model based on equations (1) and (2) will be estimated for the determinants of household wealth accumulation using the econometric software STATA 13.0.

\section{Data Setting}

\section{Presentation of data and measures of child health}

Knowing and improving child health measurement as well as measuring accurately its complex dimensions are the next challenges as it can serve the purpose of improving the quality of decision making and the quality of economic evaluation of health. Health statistics are necessary inputs in this purpose and that question was already asked in 1992 by Starfield when he underlined the lack of information on chronic illness in routinely collected data. The DHS 2011 was designed to assist in the study of the demand for health care inputs, production of reproductive health outcomes such as nutritional status of children and links existing between the different sections of the questionnaire, files containing information on individuals and households characteristics were used for our purpose. At the level of individuals, information compiled includes: demographic characteristics, mother socioeconomic characteristics and anthropometric characteristics of children aged 0-59 months. At the household level, among other things, the survey gathered information on access to basic social services (health facility, education and employment), land ownership, place of residence and wealth index.

We analyze data on 0 to 59 months old, children born to female respondents in the 2011 Demographic and Health Survey. The 2011 DHS that has 11732 observations under study. We focus on preschool age children since the largest inputs of a mother's time would traditionally be directed at these children. Restricting the sample to the preschool group also enable us to obtain results uncontaminated by other social factors, for instance the possibility of the child living with another person at that tender age is practically difficult. Respondents in the 2004 and 2011 DHS were aged 15 to 49, thus our sample consists of children with relatively productive mothers that are prone to participate in the job market, also an advantage of our focus on children's health during the preschool years is that parental inputs are likely to be particularly important, whereas educational attainment and IQ at adulthood may be influenced by a variety of other factors for which it is difficult to control. Our data of DHS also permits us to construct exceptionally detailed control variables which better enable us to identify the ceteris paribus effects of child health on maternal labour supply.

The endogenous anthropometric measure of child health is WAZ. As noted in the literature, weight-for-age reflects the combination of height-for-age and weight-for-height $\mathrm{z}$-score. Weight-for-height is thought to be a good shorter-run measure of nutritional and health status [25]. Therefore, the dependent variable used here is the Weightfor-age (haz). The exogenous variables, instrument used and the interaction term are all specified in the descriptive statistics table.

\section{Empirical Estimates}

In this section, we present a description of the characteristics of maternal labour force participation including other factors impacting on maternal labour force participation outcomes, the results of marginal estimates of child health effects on MLFP (probit, 2SLS and ivprobit). Lastly, we present the average marginal estimates of mother occupation and marital status in labour participation.

\section{Weighted sample descriptive statistics}

From Table 1 we observe that about $40 \%$ of household live in urban centers and $60 \%$ in rural area with a household size average of about 10.47. As concerns sex of household, there are $85.9 \%$ male headed households with an average child health of $-1.179 \%$ of children ranging from 0 to 59 months. There is equal distribution of sex $49 \%$ male and $51 \%$ female children and a mean year of schooling in complete years being 4.98 years. Still in this statistical table about $7.34 \%$ of women are working in the agricultural sector with 4.47 mean years of completed years of schooling.

The data shows that $89.2 \%$ of households among the many respondents of the 2004/2011 DHS were asset non-poor. In 2011, many men and women went to school with an average year of schooling of about 2.7 in both sexes as compared to their counterparts in 2004. Most women in households in the 2011 year of data collection were classified in to 5 years interval of age group with the majority of age-group being the $25-29$ age-groups with a mean percentage of $26.8 \%$. About $79.69 \%$ of these mothers gave birth to babies with a large child size.

From Table 1, there were about 11732 children whose data on Weight for age was available and data for children was collected for 
Citation: Tambi MD (2017) Children's Health, Maternal Labour Supply and Wealth Accumulation: Theory, Evidence and Policy Approach. Health Econ Outcome Res Open Access 3: 135. doi: 10.4172/2471-268x/1000135

Page 7 of 10

children between 0 to 59 months (i.e., under five years). Considering the full sample observations, about $68 \%$ of mothers participated in work or was available to work while $32 \%$ were either house wives not actually engage in the labour market or were just schooling. In this study, the outcome variable is mother labour participation, the endogenous determinant variable is weight-for-age standard deviations from the reference median (waz), the endogenous instrument used is the child characteristic (large child size), while the exogenous covariates are: mother's educational level, measured in completed years of schooling, mother's age, cluster mean of tetanus immunization status, cluster mean of time taken to fetch water, father's age, occupation, interaction of mother times father's education, intercept of mother education, child female siblings, sex of household head and household urban residence. Other authors in this domain have used similar variables and obtain similar analysis.

Large child size at birth (79\%), mother's education, and mother's age, time spent in fetching water, immunization status, sex of household head as well as other covariates of the labour market depicts the same story for both mother participant and non-participant. However, the cluster mean of mother immunization in mother participating in the job market is much lower (35.9\%) as compared to those of nonparticipating mothers (36.6\%) revealing that mothers not in job market have much time to spend with their children. We equally observed that in 2011 data set, many mothers not working lived in urban centers, nevertheless, this can be due to the available land for cultivation in the rural area as compare to white collar jobs in urban area. This is true in the case of rural Cameroon, where land is available for mothers to work.

\section{Basic marginal effect estimates of maternal labour force participation}

To determine the basic marginal effect of child health on maternal labour force participation, Table 2 presents the results of OLS and 2SLS estimates. Given that 2SLS estimation allows us to scale the reducedform effect into the effect of an increase in our ordinal child health measure. The result of 2SLS first-stage captures the impact of large child size on MLFP without specifying the pathway for this impact. Our main results are 2SLS of equation (3).

The OLS estimate indicates that child health is inversely proportional to MLFP. This result implies that an average marginal decrease in child health will increase the probability of maternal labour force participation by -0.012 . This result is not consistent with the result of Frijters et al. they noted that increasing the number of skill areas in which the child is less competent by one, reduces maternal participation by $3 \%$ age points. However, the difference in this observation may be explained by the fact that these single-equation estimates may be upward or downward biased depending upon the effect that maternal employment has on child health and on the correlation between omitted variables and child health. For example, if maternal employment has a positive impact on poor child health, and then we would expect the OLS estimate of $\mathrm{k}_{1}$ to be biased upward, that is, the unobserved maternal ability and child health are positively correlated biasing the single equation results.

The results of 2SLS first stage of column 3 show that large child size at birth significantly affects child health by $27.71 \%$ point, most

\begin{tabular}{|c|c|c|c|c|c|}
\hline Variable & OBS & Mean & SD & Min & Max \\
\hline \multicolumn{6}{|c|}{ Dependent variable } \\
\hline Mother labour market participation ( $1=$ mother participates, 0 otherwise) & 11732 & 0.681 & 0.466 & 0 & 1 \\
\hline Normalized household wealth accumulation & 11732 & 0.892 & 0.140 & 0 & 1 \\
\hline \multicolumn{6}{|c|}{ Potentially endogenous determinants of child health } \\
\hline Child health (WAZ) & 8213 & -1.179 & 1.615 & -5.99 & 5.71 \\
\hline \multicolumn{6}{|c|}{ Potential instrument for endogenous input } \\
\hline Child size at Birth (1=large size at birth, 0 otherwise) & 19857 & 0.796 & 0.402 & 0 & 1 \\
\hline \multicolumn{6}{|c|}{ Exogenous explanatory variables } \\
\hline Mother's education in years of schooling & 11732 & 4.474 & 3.941 & 0 & 17 \\
\hline Mother's education x 2011 dummy & 11732 & 2.703 & 3.840 & 0 & 17 \\
\hline Mother's occupation ( $1=$ mother works in the agricultural sector, $0=$ otherwise) & 11732 & 0.073 & 0.261 & 0 & 1 \\
\hline Cluster mean of time taken by mother to fetch water (time_mpu) & 24.107 & 16.388 & 23.012 & 17.083 & 24.616 \\
\hline Cluster mean of mother's tetanus immunization status & 0.361 & 0.162 & 0.366 & 0.157 & 0.359 \\
\hline Mother in $15-19$ years Age Group & 11732 & 0.082 & 0.274 & 0 & 1 \\
\hline Mother in $20-24$ years Age Group & 11732 & 0.237 & 0.425 & 0 & 1 \\
\hline Mother in 25-29 years Age Group & 11732 & 0.268 & 0.443 & 0 & 1 \\
\hline Mother in 30-34 years Age Group & 11732 & 0.199 & 0.399 & 0 & 1 \\
\hline Mother in 35-39 years Age Group & 11732 & 0.127 & 0.333 & 0 & 1 \\
\hline Mother in 40-44 years Age Group & 11732 & 0.065 & 0.246 & 0 & 1 \\
\hline Household size & 11732 & 10.479 & 6.200 & 1 & 44 \\
\hline Household size squared & 11732 & 148.276 & 213.977 & 1 & 1936 \\
\hline Father's education in years of schooling & 11732 & 4.985 & 4.848 & 0 & 17 \\
\hline Mother's $\mathrm{x}$ father's education & 11732 & 33.98 & 48.27 & 0 & 289 \\
\hline Sex of child ( $1=$ male, 0 otherwise) & 11732 & 0.493 & 0.499 & 0 & 1 \\
\hline Male sons in the house & 11732 & 1.566 & 1.358 & 0 & 9 \\
\hline Area of Residence ( $1=$ urban, $0=$ otherwise) & 11732 & 0.401 & 0.490 & 0 & 1 \\
\hline Male household heads $=1,0$ otherwise & 11732 & 0.859 & 0.347 & 0 & 1 \\
\hline
\end{tabular}

Source: Computed by the author from the 2004/2011 pooled Cameroon DHS, N/B: Figures are sample Means and Standard Deviation and values in the table are presented in to three significant figures

Table 1: Weighted sample statistics for short listed variables to be used in regression. 


\begin{tabular}{|c|c|c|}
\hline Variable & OLS & IV 2SLS \\
\hline child health & $-0.033^{*+*}(-3.37)$ & $0.169^{* * *}(3.19)$ \\
\hline Child Size at Birth (1=large size at birth, 0 otherwise) & $0.103^{*+*}(2.64)$ & $\mathrm{n} / \mathrm{a}$ \\
\hline Mother's education in years of schooling & $0.017^{\star *}(2.04)$ & $0.001(0.14)$ \\
\hline Mother's education x 2011 dummy & $0.019^{* *}(2.45)$ & $0.004(1.47)$ \\
\hline Mother's Occupation (1=agriculturalist, 0 otherwise) & $1.456^{*+*}(13.92)$ & $0.301^{* * *}(12.31)$ \\
\hline Mother's Age & $0.047^{\text {*** }}(15.49)$ & $0.013^{* * *}(12.15)$ \\
\hline Cluster mean of time taken by mother to fetch water (time_mpu) & $0.001(0.0 .68)$ & $0.000(0.28)$ \\
\hline Cluster mean of mother's tetanus immunization status & $0.507^{* * *}(4.56)$ & $0.113^{* * *}(2.72)$ \\
\hline Sex of Household head ( $1=$ male, 0 otherwise) & $-0.092(-2.22)$ & $-0.027(-1.58)$ \\
\hline Father's Age & $-0.007^{*+*}(-4.02)$ & $-0.001(-1.12)$ \\
\hline Father's occupation (1=skill labour, 0 otherwise) & $-0.073^{* *}(-2.17)$ & $-0.025^{*}(-1.86)$ \\
\hline Mother's $\mathrm{x}$ father's education & $-0.001^{* * *}(-3.07)$ & $-0.001^{*+*}(-4.63)$ \\
\hline Female siblings alive in the household & $0.026^{\star}(1.83)$ & $0.006(1.19)$ \\
\hline Place of residence ( $1=$ urban, 0 otherwise) & $-0.465^{* * *}(-13.41)$ & $-0.209^{* * *}(-10.93)$ \\
\hline 2011 dummy & $0.045(0.88)$ & $-0.002(-0.12)$ \\
\hline Constant & $0.782^{* * *}(-7.49)$ & $0.617^{* * *}(6.41)$ \\
\hline LR chi2/F2: Prob > chi2 & $983.46[15 ; 0.0000]$ & $44.71[14,8141 ; 0.0000]$ \\
\hline Number of observation & 11732 & 11732 \\
\hline
\end{tabular}

Table 2: Marginal effects of child health on maternal labour force participation. Dependent variable: mother labour participation.

importantly; the instrument is significant at $1 \%$ level. With respect to instrument validity and relevance, we observed that the Sargan statistic (over-identification test of all instruments) is 0.000 ; while Cragg-Donald F statistic (weak identification test) is 39.391 indicating that we have a strong instrument that is also relevant. Further, the endogeneity test of endogenous regressors (haz) is 16.666 it has augment the practicability and robustness of our results. Following Ong et al. this result is strongly supported by other studies, as they noted that the size of the child at birth is a strong determinant of the health of the child.

The main result is 2SLS; they represent the estimates of $\mathrm{k}_{1}$ from equation (4) which corresponds to the 2SLS of the effect of child health on maternal labour force participation. Calculating the effects of child health effects on MLFP using 2SLS, we observed that an increase in child health has a probability effect of 0.169 to increase maternal labour participation and this result is statistically significant at $1 \%$ level. These results are quite consistent with the study of Powers; Dunkelberg and Spiess and that of Frijters et al. From the above, the decision makers should always take measures to measure the unintended outcomes of job policies as well as secure the policy evaluation data. Lastly, more flexible work arrangements enabling mothers to work from home would help those with disabled children to participate to some degree in the labour force.

Our results are an important contribution to knowledge within this area in Cameroon. In addition, our results have important consequences for the literature that examines impact of child health on maternal employment. Given the difficulty in finding a variable that is correlated with child health and not maternal employment (an instrument), most studies struggle to identify the causal impact. Our results therefore provide new evidence on the likely direction and size of bias in previous studies' estimate. Considering the 2SLS results of haz and whz, we observed that Child health increases the probability of MLFP significant at 5\% level for both for waz and whz. In line with other studies in this domain [13] this result implies that at least for a probability of 0.27 child health increases maternal labour force participation. Thus, when a family is presented with a child with health problem, it often exerts emotional stress and imposes a physical demand for caring on family members. A family member, usually the mother as the primary cared, consequently reduces work commitment or even leaves the labour force to care for their ill children. Hence, to provide a safety net to the affected families and children, the government needs to offer financial or related support.

\section{Household wealth accumulation production function}

Table 3 presents estimates of the wealth accumulation function under different assumptions using child health (waz) as the main independent variable, while controlling for other correlates. As seen in Table 3, the OLS estimates of the structural parameters and the survey-based 2SLS estimates accounts for endogeneity. Checking the validity, relevance and robustness of this result, we observed that the weak identification test: Cragg-Donald F-Stat [10\% maximal IV relative bias] is 44.666 [16.38], implies we reject the possibility that our instrument (large child size) is weak. The diagnostic tests of Durbin-Wu-Hausman Chi2 test for exogeneity of the potential endogenous variables [df: p-value] of 6.440 [0.0112] shows that we rejects exogeneity of child health in the household asset endowments production function. Further, the coefficient of the predicted residual of child health (coefficient $=-0.193 ; \mathrm{t}=-2.47$ ) in column 4 is statistically significant (though negative), confirming that this input into household asset endowments is indeed endogenous, so that inclusion of this residual term in the health generating equation, as in above, is required for consistent estimation of structural parameters

The results of OLS reveal that child health is negatively and significantly associated to household wealth. Critically, the results of OLS (-0.5\%) on child health are clearly not representative (truncation) of the underlying population whereas the other columns give surveybased regression models that are representative of the underlying population.

The 2SLS estimates (15.6\%) of the structural parameters accounts for endogeneity of child health, according to this 2SLS estimates, child health increases the acquisition of household wealth accumulation such as houses, cars, telephones, television, radio and telephone. The result shows that child health is positively and significantly associated 


\begin{tabular}{|c|c|c|}
\hline Variables & OLS & IV 2SLS \\
\hline Child health & $-0.005^{* * * *}(-7.18)$ & $0.156^{*}(1.87)$ \\
\hline Mother's education & $-0.006^{* * *+}(-9.30)$ & $-0.051^{* * * *}(-8.37)$ \\
\hline Mother's education x 2011 dummy & $-0.003^{*+*+1}(-4.78)$ & $-0.026^{*+*}(-5.15)$ \\
\hline Mother works in the agricultural sector, & $0.011^{* *}(2.30)$ & $0.114 *(2.78)$ \\
\hline Mother in $15-19$ years Age Group & $0.048^{\cdots *}(4.87)$ & $0.373 * \cdots(4.66)$ \\
\hline Mother in $20-24$ years Age Group & $0.051^{\cdots \cdots}(5.49)$ & $0.429 \cdots(5.54)$ \\
\hline Mother in 25-29 years Age Group & $0.044^{* \prime \prime}(4.88)$ & $0.386^{* * * *}(5.02)$ \\
\hline Mother in $30-34$ years Age Group & $0.039 \cdots *(4.40)$ & $0.325 \cdots(4.37)$ \\
\hline Mother in $35-39$ years Age Group & $0.009 * \cdots(3.66)$ & $0.299^{* * *}(3.86)$ \\
\hline Mother in $40-44$ years Age Group & $0.027^{\prime \prime \prime}(2.75)$ & $0.241^{\prime \prime *}(2.98)$ \\
\hline Household size & $-0.002^{+* * *}(-3.86)$ & $-0.019^{+* *+}(-3.72)$ \\
\hline Household size squared & $0.000 *(2.24)$ & $0.000^{* *}(1.97)$ \\
\hline Male household head & $-0.025^{+3 * *}(-7.29)$ & $-0.195^{* * * *}(-6.91)$ \\
\hline Father's education in years of schooling & $0.004 * \cdots(9.26)$ & $0.034^{\cdots \cdots}(8.80)$ \\
\hline Mother's $\mathrm{x}$ father's education & $-0.001^{*+* t}(-17.31)$ & $-0.008^{* * * *}(-15.83)$ \\
\hline Male child & $-0.005^{* *}(-2.15)$ & $-0.022(-0.99)$ \\
\hline Presence of sons in the house & $0.003^{\cdots *}(3.27)$ & $0.030 \cdots(3.29)$ \\
\hline Urban residence & $-0.089^{* * * *}(-34.27)$ & $-0.736^{* * *+}(-23.05)$ \\
\hline 2011 dummy & $-0.008^{* *}(-2.10)$ & $-0.064^{* *}(-2.01)$ \\
\hline Child health residual & n/a. & $\mathrm{n} / \mathrm{a}$ \\
\hline Child Health $\times$ its residual & $\mathrm{n} / \mathrm{a}$ & $\mathrm{n} / \mathrm{a}$ \\
\hline Inverse of the Mills ratio & $\mathrm{n} / \mathrm{a}$ & $\mathrm{n} / \mathrm{a}$ \\
\hline Constant & $0.971^{\text {tw+t }}(88.76)$ & $0.785 *(5.21)$ \\
\hline R-squared/ Pseudo $R^{2}$ & -0.634 & 0.331 \\
\hline Log of likelihood & 5692.184 & $\mathrm{n} / \mathrm{a}$ \\
\hline F-Stat [df: p-val] & $\begin{array}{l}4418.83[19 ; \\
0.0000]\end{array}$ & $\begin{array}{c}265.76[19,8193 ; \\
0.000]\end{array}$ \\
\hline $\begin{array}{l}\text { Weak identification test: Cragg-Donald } \\
\text { F-Stat [10\% maximal IV relative bias] }\end{array}$ & $\mathrm{n} / \mathrm{a}$ & $44.666[16.38]$ \\
\hline $\begin{array}{l}\text { Durbin-Wu-Hausman Chi2 test for } \\
\text { exogeneity of the potential endogenous } \\
\text { variables [df: p-value] }\end{array}$ & $\mathrm{n} / \mathrm{a}$ & $6.440[0.011]$ \\
\hline Number of observations & 11732 & 11732 \\
\hline
\end{tabular}

Table 3: Household wealth accumulation production function under differen assumptions.

with the production of household wealth, captured by weight-for-age $\mathrm{z}$-score. This implies that if a child is in good health, the household may benefit from potential savings on medical expenditures, extra-time that could be redeployed to additional income earning activities that improve household income and enhance the acquisition of household asset. This result also implies that using the correct estimation procedure is critical for policy implications [2].

More generally, better child health increases household income through potential savings that could be realized on health expenditures and indirectly through extra-time that could be redeployed to additional labour market participation opportunities. The key argument here is not that child health directly increases household income, but that better child health elicits extra-time, which is strongly correlated with enhanced training and labour market participation possibilities that increase household income [2]. The results of haz and whz shows similar tendencies as in waz to revealing that child health has both direct and indirect effects on household asset endowments. The haz and whz results also confirm the appropriateness of our results. In addition to the strength of the study, the parameter estimates of the one identifying child health variables are jointly significant $(\mathrm{p}<0.000)$, according to the Anderson-Rubin F-statistics of 44.654. These results are clearly summarized in Table 3.

\section{Conclusion}

The preoccupation of this study has been to develop a conceptual framework based on exploring the link between child health, maternal labour and wealth accumulation. This is, in an attempt to show the centrality and importance of child health in understanding: Health determinants, maternal labour supply and wealth accumulation for broader appreciation. In particular, we have attempted to look at the theoretical insights on children's health, maternal labour and wealth accumulation and on the intersection of children's health on maternal labour and wealth accumulation. We have equally presented the empirical evidence on the central role of children's health on maternal labour and wealth accumulation. Thus, this study attempts to tests the following hypotheses based on empirical evidences: children's health is instrumental in accounting for maternal labour and children's health is strongly associated with higher levels of wealth accumulation.

We observed that children's health positively and significantly influenced health at old age; children's health is instrumental in accounting for maternal labour and children's health is significantly associated with higher levels of wealth accumulation. From policy point of view, investing in child health, given the appropriate medical care/prenatal care from utero is an important enabler for households and women in particular to use the extra-time at their disposal to participate additionally in labour market, this can engender income growth, reduce poverty and initiate the process of accumulation of human capabilities.

\section{References}

1. Aguayo-Rico A, Guerra-Turrubiates I, Ricardo M (2005) Empirical evidence of the impact of health on economic growth. J Polit Econ 14

2. Baye M, Fambon S (2010) Parental literacy and child health production in Cameroon. Afr J Econ Policy 17: 99-130.

3. Behrman J, Rosenzweig M (2004) Returns to Birthweight. Rev Econ Stat 86 586-601.

4. Levine D (1993) The effect of non-traditional attitude of married women's labour supply. J Econ Psychol 14: 655-679.

5. World Health Organization (WHO) (2006) Policy brief, integrating sexual and reproductive health services. Geneva: World Health Organization.

6. World Health Organization (WHO) (1986) Health, health policy and economic outcomes; health and development satellite. WHO Director General, Transition Team, Geneva.

7. World Health Organization (WHO) (2001) Macroeconomics and health: investing in health for economic development. Geneva: World Health Organization.

8. Ako S, Fokoua S, Sinou T, Leke R (2008) Reproductive health in Cameroon WHO Collaborating Centre for Research in Human Reproduction. Geneva Foundation for Medical Education and Research.

9. Tambi D, Njong M, Baye F (2014) Linking child health, maternal labour force participation and household asset endowments in Cameroon: what the people say. Russian Journal of Agricultural and Socio-Economic Sciences 10.

10. Dow H, Philipson J, Sala-i-Martin X (1999) Longevity complementaries under competing risks. Am Econ Rev 89: 1358-1371.

11. Mwabu G (2009) The production of child health in kenya: a structural model of birth weight. J Afr Econ 18: 212-260.

12. Tambi D, Nkwelle J (2013) Child health and maternal labour supply: a chi square approach. Int J Financ Econ Manag.

13. Bategeka L, Asekenye O, Barungi M, Apolot M (2009) The determinants of birth weight in Uganda. A final report submitted to AERC, Nairobi Kenya.

14. Kiiskinen $U$ (2002) A health production approach to the economic analysis of health promotion. Academic dissertation for the degree of doctor of Philosophy, Department of Economics and Related Studies, University Press, University of York, UK. 
Citation: Tambi MD (2017) Children's Health, Maternal Labour Supply and Wealth Accumulation: Theory, Evidence and Policy Approach. Health Econ Outcome Res Open Access 3: 135. doi: 10.4172/2471-268x/1000135

15. Sherraden M (1991) Assets and the poor: a new American welfare policy.

16. Kanter R (1977) Men and women of the corporation. NY: Basis Book.

17. Carroll C (1997) Buffer-stock saving and the life cycle/permanent income hypothesis. Quart J Econ 12: 1-55.

18. Basu B, Basu B (1991) Economic woes not comparable to 1991 crisis, World Bank Chief, World Bank. PSU Press Release.

19. Mirvis DM, Chang CF (2003) The relationship between health and economic development: health as an economic engine. Health policy reports. The Center for Health Services Research, University of Tennessee, USA.

20. Salkever D (1982) Children's health problems and maternal work status. In: J Human Resources 17: 94-109.
21. Meyers C, Gluck M, Mark A (1996) Child support and welfare dependence: a multinomial logit analysis. Demography 22: 367-380.

22. Mcdonald $P$ (2003) Mapping patterns and perceptions of maternal labour force Participation: influences, trade-offs and policy implications. Thesis submitted as partial fulfillment for the degree of doctor of philosophy, school of psychology and counseling. Queensland University of Technology, Queensland, Australia.

23. Becker G (1965) A theory of the allocation of time. The Econom J 75: 493-517.

24. Strauss J, Thomas D (1998) Health, nutrition, and economic development. J Econ Literat 36: 766-817.

25. Falkner F, Tanner T (1986) Developmental biology: prenatal growth. Human Growth Series. 